INTERNATIONAL HIGHER EDUCATION Number 75 Spring 2014

Pages 15-16

\title{
Will China Excel in the Global Brain Race?
}

QIANG ZHA

Qiang Zha is an associate professor at the Faculty of Education, York University, Toronto, Canada. E-mail: qzha@edu.yorku.ca.

In the past decade, China appears to have been taking a strong position in the global brain race. Following the well-known "Thousand Talent Program" (including "Thousand Young Talent Program" and "Thousand Foreign Talent Program"), which aims to lure back expatriate and international talent, the Chinese government recently launched a "Ten Thousand Talent Program." This program, unlike the former, focuses on home talent and pledges to select and support 10,000 leading scholars in the next 10 years in fields of sciences, engineering, and social sciences-among whom the top 100 will be compelled to aim at seizing Nobel prizes. So, China now explicitly raised its ambition up to the standard of an innovation leader, to rely more and more on domestic talent. Indeed, the "Thousand Talent Program" did not really meet the expectations. So far, the high caliber expatriate talent did not go back to China in a large scale. Among the returnees, those possessing doctorate, master's, and bachelor's degrees show an odd ratio of 1:8:1. However, a majority of returnees are those who spent a short while overseas, to study for a master's degree. Statistics show that over 1.5 million Chinese scholars and students remain abroad. What caused 
China's global brain strategy (famous for handsome salaries, generous start-up packages, and other financial incentives) to not have produced the expected outcomes?

\section{Perspectives}

An adoption of the views of human, cultural, and social capital may offer an insightful interpretation of this puzzling scenario. For example, an impetus that inspires Chinese scholars or students to go back to China might be the limitation associating with human capital logic, which puts emphasis on technical and tangible knowledge gained from various education and training. Supposedly, Chinese expatriates feel they are largely treated as human capital in their host countries and see few opportunities to fulfill their cultural and social capital in that specific context. Then, do the initiatives like the "Thousand Talent Program" provide the equivalent pull factor? - not necessarily, as such programs are also primarily based on human capital logic. Many Chinese expatriates may see better chances to enjoy their cultural capital back in China, which distinguishes from human capital as the implicit knowledge gained from the cultural tradition and environment, and often defines a higher status in society. However, when it comes to accomplishing social capital, they will find they have "ceilings" in China, too.

Arguably, modern social capital conceptualization attaches more importance to individual free choice, in order to create a more cohesive society. In the Chinese social context, however, social capital has been closely linked with the concept of guanxi (personalized networks of influence), in particular connections with powerful bureaucrats. In this regard, most returnees do not 
enjoy an advantage but rather suffer a disadvantage, given their spatial separations from China (for a couple of decades in some cases). This is particularly true in recent years when the Chinese model for development has showcased some successful aspects (China quickly rises as the world's secondlargest economy) and garnered confidence (China is anticipated to surpass the United States and become the wealthiest nation around 2020). Against this backdrop, those policies and practices that bear the Chinese characteristics are hardly allowed to be changed by ideas and personnel from the outside.

\section{The Cases of Rao and Shi Reveals a Paradox}

Two prominent returnee scientists were Rao Yi and Shi Yigong. Rao Yi was a professor of neurology at Northwestern University in the United States. He returned to Peking University in 2007 to take up the position of dean of the College of Life Science. Shi Yigong was the Warner-Lambert/Parke-Davis professor at Princeton University. In 2008, he resigned his position at Princeton University and started pursuing his career at Tsinghua University-as the dean of life science there. They are both regarded as the top-flight talent lured back by the "Thousand Talent Program."

Apparently, both Rao Yi and Shi Yigong did not prepare to go back to China as a pure researcher. Rather, they wish to make a difference and to better China's research culture and university education, riding on their social capital. This is evident in their responses to questions as to why they chose to go back to China, as well as in their own writings. In a coauthored article published in 2010 in Science, Shi and Rao openly claimed that China's current research culture "wastes resources, corrupts the spirit, and stymies innovation." Specifically, they 
cited the bureaucratic approach to deciding research funding as the source that "stifles innovation and makes clear to everyone that the connections with bureaucrats and a few powerful scientists are paramount." They went on to disclose that "[T]o obtain major grants in China, it is an open secret that doing good research is not as important as schmoozing with powerful bureaucrats and their favorite experts." They became frustrated to observe that such a problematic research culture "even permeates the minds of those who are new returnees from abroad; they quickly adapt to the local environment and perpetuate the unhealthy culture," and called for a meaningful reform in order to build a healthy research culture.

While Shi and Rao were disturbed to see that many colleagues choose to be silent in face of such an "unhealthy culture" for fear of "a losing battle," they seem to have become victims of their own proclaimed war against a perceived unhealthy academic culture. After two unsuccessful attempts in a row, Rao announced his boycott of competing for a fellowship at the Chinese Academy of Sciences, while Shi is still waiting for the result of his second bid. If prominent returnees, like Rao and Shi, suffered from vulnerability of their social capital in face of the corrupt research culture, how could domestic talent selected by the “Ten Thousand Talent Program" be able to break it?

In the cases of Rao and Shi, their cultural capital appears to be estranged into publicity resource of the government. Despite their fight against the bureaucracy, they are now often cited as part of the success of the "Thousand Talent Program." In the cases of many others, their social capital is mostly assimilated to the current research culture in China, which in turn prompts them to become the so-called "elegant egoists." In short, without overhauling the 
current research system and culture in China, it is not an easy task for the initiatives such as the "Thousand Talent Program" or "Ten Thousand Talent Program" to accomplish their goals. Last but not least, a message could also be sent to Western systems that have been absorbing a bulk of global talent. If no sufficient attention is paid to cultural and social capital of global talent, then there could be a looming crisis that will shake the magnet position of those systems to global talent.

Note: On December 19,2013, Shi Yigong was appointed a new member of the Chinese Academy of Sciences, following his elections into both the US National Academy of Sciences and the American Academy of Arts and Sciences in April 2013, as a foreign associate or foreign honorary member. 